\title{
Novel Cues Reinstate Cocaine-Seeking Behavior and Induce Fos Protein Expression as Effectively as Conditioned Cues
}

\author{
Ryan M Bastle', , Peter R Kufahl ${ }^{1,3}$, Mari N Turk', Suzanne M Weber ${ }^{2}$, Nathan S Pentkowski ${ }^{2}$, \\ Kenneth J Thiel' and Janet L Neisewander*, ,,2 \\ 'Department of Psychology, Arizona State University, Tempe, AZ, USA; ${ }^{2}$ School of Life Sciences, Arizona State University, Tempe, AZ, USA
}

\begin{abstract}
Cue reinstatement of extinguished cocaine-seeking behavior is a widely used model of cue-elicited craving in abstinent human addicts. This study examined Fos protein expression in response to cocaine cues or to novel cues as a control for activation produced by test novelty. Rats were trained to self-administer cocaine paired with either a light or a tone cue, or received yoked saline and cue presentations, and then underwent daily extinction training. They were then tested for reinstatement of extinguished cocaine-seeking behavior elicited by response-contingent presentations of either the cocaine-paired cue or a novel cue (that is, tone for those trained with a light or vice versa). Surprisingly, conditioned and novel cues both reinstated responding and increased Fos similarly in most brain regions. Exceptions included the anterior cingulate, which was sensitive to test cue modality in saline controls and the dorsomedial caudate-putamen, where Fos was correlated with responding in the novel, but not conditioned, cue groups. In subsequent experiments, we observed a similar pattern of reinstatement in rats trained and tested for sucrose-seeking behavior, whereas rats trained and tested with the cues only reinstated to a novel, and not a familiar, light or tone. The results suggest that novel cues reinstate responding to a similar extent as conditioned cues regardless of whether animals have a reinforcement history with cocaine or sucrose, and that both types of cues activate similar brain circuits. Several explanations as to why converging processes may drive drug and novel cue reinforcement and seeking behavior are discussed.

Neuropsychopharmacology (2012) 37, 2109-2120; doi:10.1038/npp.2012.60; published online 25 April 2012
\end{abstract}

Keywords: cocaine; self-administration; drug-seeking behavior; novelty; reinstatement; immediate early gene

\section{INTRODUCTION}

Since the early 1990s, the drug addiction field has given much attention to uncovering the mechanisms of craving and relapse using the extinction/reinstatement animal model (Bossert et al, 2005). This procedure allows researchers to examine individual factors known to elicit drug-seeking behavior and can identify potential interventions aimed at attenuating drug craving. The face validity of the model, particularly with cue reinstatement, is demonstrated by the corresponding increase of craving reported by human addicts when presented with cocaine-related stimuli (Childress et al, 1988; Ehrman et al, 1992) and the return of drug-seeking behavior in animals when presented with cues previously paired with cocaine reinforcement (Markou et al, 1993; Shaham et al, 2003). Both of these measures are thought to reflect incentive motivational

*Correspondence: Professor JL Neisewander, School of Life Sciences, Arizona State University, PO Box 87450I, Tempe, AZ 85287-450I, USA, Tel: + 480965 0209, Fax: + 4809658544 ,

E-mail: janet.neisewander@asu.edu

${ }^{3}$ These authors contributed equally to this work.

Received 25 January 2012; revised 28 March 2012; accepted 30 March 2012 effects of the cues acquired through classical conditioning (Stewart, 1983). Further evidence supporting the construct validity of the model are that neuroimaging studies in human addicts and examination of immediate early gene (IEG) expression in animals that reveal the same brain regions are activated by cocaine-paired cues (Childress et al, 1999; Garavan et al, 2000; Grant et al, 1996; Kufahl et al, 2009; Wang et al, 1999; Zavala et al, 2008). In addition, compounds found to decrease self-reports of craving in humans have been shown to attenuate cue-elicited drug-seeking behavior in animals (Fuchs et al, 1998; Yahyavi-FirouzAbadi and See, 2009), demonstrating predictive validity and overall utility of the cue reinstatement model.

Fos protein expression is an established method for identifying brain circuits associated with cocaine-induced conditioning effects (Brown et al, 1992; Crawford et al, 1995; Neisewander et al, 2000). Fos is a product of the IEG $c$-fos, an inducible transcription factor important for the initiation of many signal transduction pathways (Curran and Morgan, 1995). When an animal undergoes physiological and/or pharmacological manipulations, $c$-fos is transiently induced in relevant brain areas, with the resulting Fos protein expression yielding a histological marker of stimulus-induced brain activity (Chaudhuri, 1997; Harlan 
and Garcia, 1998). In response to cocaine or cocaine-paired cues, Fos is expressed in brain regions commonly associated with reward processing, memory, and drug abuse (Ciccocioppo et al, 2001; Hotsenpiller et al, 2002; Neisewander et $a l, 2000)$. More recently, we found that presentation of response-contingent cocaine-paired cues during reinstatement testing induced a widespread pattern of Fos expression throughout the brain, including several prefrontal cortical, limbic, and striatal subregions (Kufahl et al, 2009). Although the association between cue presentation and brain activation appears to rely on previous drug-stimulus pairings (Guo et al, 2008; Miller and Marshall, 2005), little attention has been given to the contribution of novelty on test day. While cue-elicited reinstatement of cocaineseeking behavior depends to some extent on the sensory characteristics of the cues (See et al, 1999), the propensity for animals to be aroused or motivated by environmental or procedural novelty could also contribute strongly to both behavior and Fos expression (Badiani et al, 1998; Bardo et al, 1989, 1996).

The purpose of this study was to investigate the specificity of both the reinstatement of cocaine-seeking behavior and its associated Fos expression. In Experiment 1, rats were trained to self-administer cocaine that was paired with presentation of either an oscillating light or tone, followed by extinction training where lever presses had no consequences. Half of the rats were then tested for reinstatement of cocaine-seeking behavior with conditioned cues and half were tested with a novel cue (that is, a cue not present during training). We hypothesized that novel cues would not reinstate cocaine-seeking behavior, but would contribute to cue-induced Fos expression in some brain regions. To control for non-motivational contributions of cue exposure to the Fos response, control rats were given saline infusions paired with cues that were yoked to reinforcement delivery in the cocaine-trained rats. In Experiments 2 and 3, we examined the specificity of the findings for drug seeking by examining rats trained with sucrose or cue-only reinforcement.

\section{MATERIALS AND METHODS}

\section{Animals \\ Male Sprague-Dawley rats were housed individually in a temperature-controlled colony with a 12-h (Experiment 1) or a 14-h (Experiments 2/3) reversed light/dark cycle and were briefly handled daily. Animal care and housing conditions were consistent with the 1996 Guide for Care and Use of Laboratory Animals (Clark et al, 1997). Surgical and experimental procedures were approved by the Institutional Animal Care and Use Committee at Arizona State University. Rats weighed $250-325 \mathrm{~g}$ before surgery or training. \\ Experiment 1: Reinstatement and Fos Expression Elicited by Cocaine-Conditioned vs Novel Cues}

Surgery. Catheters were constructed from Silastic tubing ( $10 \mathrm{~cm}$ in length, inner diameter 0.012 inches, outer diameter 0.025 inches, Dow Corning, Midland, MI) connected to a 22-G nonferrous metal cannula encased within a plastic screw connector (Plastics One, Roanoke, VA) and implanted into the jugular vein and secured to the skull with dental acrylic cement under isoflurane anesthesia (2-3\%) as described previously (Zavala et al, 2007). Incisions were sutured and treated with a topical antibiotic and the rats were given buprenorphine $(0.05 \mathrm{mg} / \mathrm{kg}$, s.c.) analgesia and an anti-inflammatory analgesic (meloxicam; $1 \mathrm{mg} / \mathrm{kg}$, s.c.). Patency of the catheters was maintained throughout the experiment by daily flushing with $0.1 \mathrm{ml}$ timentin $(66.67 \mathrm{mg} / \mathrm{ml}$; bioWORLD, Dublin, $\mathrm{OH})$ in saline solution containing 70 units $/ \mathrm{ml}$ heparin sodium. Catheter patency was tested periodically with $0.8 \mathrm{~g}$ methohexital sodium (Brevital, Sigma, St Louis, MO), a dose that produces rapid loss of muscle tone only when administered i.v. Rats were given 7 recovery days in their home cages and were handled and weighed daily.

Apparatus. Training and testing were conducted in Plexiglas operant conditioning chambers $(20 \times 28 \times 20 \mathrm{~cm})$ equipped with a food pellet dispenser and a food well located between two levers mounted on the front panel (Med Associates, St Albans, VT). A cue light was mounted above one lever, a tone generator $(500 \mathrm{~Hz}, 10 \mathrm{~dB}$ above background noise) was mounted on the side wall near a lever and a house light was mounted on the rear wall opposite the levers. The lever below the cue light and nearest to the tone generator was designated as the active lever. Each conditioning chamber was housed within its own ventilated, soundattenuating cabinet. An infusion pump containing a $10-\mathrm{ml}$ syringe was located outside of the cabinet. Tygon tubing connected to the syringe was attached to a liquid swivel (Instech, Plymouth Meeting, PA) suspended above the operant conditioning chamber. The outlet of the swivel was fastened to the catheter via Tygon tubing that ran through a metal spring leash (Plastics One). The leash was fastened onto the plastic screw of the cannula that was anchored on the animal's head.

Self-administration (SA) training. SA training was conducted during daily 2-h sessions. Rats were trained to press the active lever to receive cocaine reinforcement $(0.75 \mathrm{mg} / \mathrm{kg} / 0.1 \mathrm{ml}$, i.v. $)$. Upon completing a schedule of reinforcement, either the oscillating cue light or tone was activated, followed $1 \mathrm{~s}$ later by activation of the infusion pump for $6 \mathrm{~s}$. Following infusion, the cue light or tone was inactivated. After a 20-s timeout period, responses on the active lever were accumulated toward the next reinforcement schedule. Note that rats receiving the tone $v s$ light cues were trained in separate rooms so that the tone would be completely novel to animals that were trained with the light cue.

All animals began on a fixed ratio (FR) 1 schedule of reinforcement with the capability to progress to a variable ratio (VR) 2, VR3, and finally VR5 schedule. After ending the session on a VR5 schedule for two consecutive days, the animals then began the remaining sessions on a VR5 schedule. All animals were restricted to $16 \mathrm{~g} /$ day of food beginning 2 days before training to facilitate acquisition of SA (Carroll et al, 1981) with a graded increase $(18,20$, and $22 \mathrm{~g} /$ day) as they progressed from an FR1 to a VR5 schedule of reinforcement. Animals were then given food ad libitum for the rest of the experiment. Note that all animals were on a VR5 schedule exclusively for at least the last 5 days of SA (that is, the acquisition criteria). Control rats received saline 
infusions, cue presentations, and underwent identical food restriction as their cocaine partner throughout SA.

Extinction training. The day after SA training was completed, rats were given daily 90 -min extinction sessions across 14-15 days. During these sessions, lever presses had no scheduled consequences; both cocaine and saline-yoked rats were connected to the swivel but no infusions or light/ tone cues were delivered. At the end of extinction training, all rats exhibited a decrease in response rates on the active lever to $<20$ responses during a session or to $20 \%$ of the peak response rate that occurred during extinction training. Responding during the terminal extinction session was used as a baseline for statistical comparison with responding on the test day.

Test for reinstatement of cocaine-seeking behavior. Cocaine-seeking behavior was operationally defined as responses on the active lever in the absence of cocaine reinforcement. On the day after the final extinction session, rats were placed in their conditioning chambers for $90 \mathrm{~min}$. The test session length was chosen for optimal expression of stimulus-induced Fos protein expression (Moratalla et al, 1993).

The cocaine rats trained with either the light or the tone cue were assigned to either a novel or a CS test cue condition (4 groups, $n=7-9$ /group). For rats in the CS test cue condition, the cocaine-paired stimulus complex (that is, oscillating cue light or tone and pump motor) was delivered on an FR1 schedule of reinforcement. For rats in the novel test cue condition, the stimulus was the oscillating tone (without the pump motor) for rats trained with the oscillating light, or vice versa, also delivered on an FR1 schedule. Responses on the active lever by saline-yoked controls had no consequences and they received yoked presentations of the same cue as their cocaine-trained counterpart (4 groups, $n=3-5$ /group).

Tissue preparation and Fos protein immunohistochemistry. Immediately following reinstatement testing, rats were deeply anesthetized with sodium pentobarbital $(100 \mathrm{mg} / \mathrm{kg}$, i.p.), perfused, and their brains were harvested and postfixed as described previously (Zavala et al, 2007). The brains were later sectioned using a sliding microtome (Microm International, Walldorf, Germany) connected to a freezing stage (Physitemp, Clifton, NJ). Serial coronal $40-\mu \mathrm{m}$ sections were collected, separated by $120 \mu \mathrm{m}$, centered at anatomical locations corresponding to bregma +3.2 , + 1.6, -2.56 , and $-5.6 \mathrm{~mm}$ (Paxinos and Watson, 1998). Tissue sections were stored at $4{ }^{\circ} \mathrm{C}$ in a cryoprotectant solution.

Sections were labeled with rabbit polyclonal anti-Fos serum (1:5000 dilution; sc-52, Santa Cruz Biotechnology, Santa Cruz, CA) followed by biotinylated goat anti-rabbit IgG antibody (1:500 dilution; Vector Laboratories, Burlingame, CA), which was visualized using $0.02 \% 3,3^{\prime}$-diaminobenzidine (Sigma-Aldrich, St Louis, MO) as described previously (Thiel et al, 2010). Sections were then mounted onto gelatin chromium-coated slides, air-dried, dehydrated, and coverslipped for light-microscopic inspection.

Fos immunoreactivity analysis. Fos immunoreactive cells were analyzed using a Nikon Eclipse E600 (Nikon Instruments, Melville, NY) microscope set at $20 \times$ magnification and counted blind to treatment conditions using ImageJ software. The anatomical boundaries of each region were determined using a rat brain atlas (Paxinos and Watson, 1998 ) as illustrated in Figure 2a. Sections taken at $+3.2 \mathrm{~mm}$ from bregma contained the $\mathrm{Cg} 1$ region of the anterior cingulate cortex $(\mathrm{Cg} 1)$. Sections taken at $+1.6 \mathrm{~mm}$ from bregma contained the $\mathrm{Cg} 2$ region of the anterior cingulate cortex $(\mathrm{Cg} 2)$, dorsomedial caudate/putamen $(\mathrm{dmCPu})$, dorsolateral caudate/putamen ( $\mathrm{dlCPu})$, nucleus accumbens shell (NAcS), and nucleus accumbens core (NAcC). Sections taken at $-2.56 \mathrm{~mm}$ from bregma included the basolateral amygdala (BlA). Sections taken at $-5.6 \mathrm{~mm}$ from bregma included the ventral tegmental area (VTA). The sections were taken such that the rostral-caudal extent of each region of interest was sampled $(340 \mu \mathrm{m})$. Fos immunoreactivity was counted and identified by black oval-shaped nuclei (Figure $2 \mathrm{c} / \mathrm{d}$ ). Each region was analyzed using both hemispheres from three tissue sections from each animal. The area of each sample measure was $0.26 \mathrm{~mm}^{2}$ and the counts from all the sample areas from a given region were averaged and scaled to provide a mean number of Fos-positive cells per $\mathrm{mm}^{2}$.

\section{Experiments 2 and 3: Reinstatement after Training with Sucrose or Cue Reinforcement Only}

Rats in Experiment 2 received response-contingent cue presentations (either the light or the tone) paired with delivery of a sucrose pellet $(45 \mathrm{mg}$, Bio-Serv, Frenchtown, $\mathrm{NJ}$ ), whereas rats in Experiment 3 received responsecontingent cue presentations with no other reinforcer during training. The latter served to examine the reinforcing effects of the cues themselves. The procedures used in these experiments were identical to those used in Experiment 1 with the following exceptions: (1) rats in Experiment 2 received approximately 30 sucrose pellets in their home cage for three days before sucrose reinforcement training in order to familiarize them with the pellets; (2) no surgery was performed on the rats from either experiment; and (3) the training, extinction, and test sessions in both experiments were only $30 \mathrm{~min}$ in duration to avoid satiation found with longer training sessions (Bizo et al, 1998) and to attain a comparable number of cue presentations per session as Experiment 1. In addition, rats in Experiment 3 were matched to sucrose rats when they transitioned from food-restriction to ad libitum access in the home cage.

\section{Statistical Analysis}

Reinforcement rates, active and inactive lever responses during extinction, and Fos-labeled cells were analyzed by analysis of variances (ANOVAs) with training cue (light, tone), test cue condition (novel, CS), test cue modality (light, tone), and drug history (cocaine, saline) as a between-subjects factors where appropriate and session as a within-subjects factor where appropriate. Analysis of covariance (ANCOVA) was conducted for test-day data with the change in inactive lever presses from baseline to test day as the covariate to account for non-specific increases in lever responses on test day. Significant interactions and main effects were followed by smaller factorials, tests for simple effects, and post hoc tests (Bonferroni or Tukey) where appropriate. Additionally, the correlation between 
test-day responses on the active lever and Fos expression in the cocaine-trained rats was calculated using the Pearson product-moment correlation $(r)$ for the novel and CS groups in Experiment 1.

\section{RESULTS}

All descriptive statistics are reported as mean \pm standard error of the mean.

\section{Experiment 1}

Cocaine SA. The 16 light-trained cocaine rats received a total of $504 \pm 46$ cocaine infusions and the 18 tone-trained cocaine rats received a total of $413 \pm 32$ cocaine infusions during SA training. This difference in infusion rates was due to the rapid acquisition of operant responding in the light-trained rats (Figure 1a). A significant interaction between session and training cue was found $\left(\mathrm{F}_{4}, 117=2.56\right.$, $p<0.05)$, where tests of simple effects revealed that on the first four days of SA, the light-trained groups achieved more infusions than the tone-trained groups (Figure 1a; ANOVAs, $p s<0.05$ ). However, analysis of total infusions across all sessions did not differ between the two training cue groups (Figure 1a inset; $t$-test, $t_{32}=1.66$, $p=0.11)$.

Extinction and reinstatement of cocaine-seeking behavior. Extinction training significantly reduced responding across sessions (Figure 1b), where a main effect of session was found on the active $\left(F_{3,82}=33.26, p<0\right.$. 001) and inactive $\left(\mathrm{F}_{4,136}=3.38, p<0.05\right)$ levers and there were no group differences in response rates. Post hoc analyses revealed that last-day extinction responses on both levers were significantly reduced from first-day responses (Bonferroni correction, $p s<0.025)$. No significant effects were found on the active or inactive lever responses in the saline-yoked groups (Table 1).

To assess reinstatement of cocaine-seeking behavior, we compared responses on the active lever during testing with responses on the active lever during the last extinction session (that is, baseline), with day as a within-subjects factor and test cue condition and test cue modality as betweensubjects factors. As the covariate (change in inactive lever presses from baseline to test day) was measured after the manipulations, we tested the homogeneity of regression and found the interaction between the covariate and test cue condition and/or modality to be non-significant (ranged from $\mathrm{F}_{1,29}=0.29$ to 0.83 , ps $>0.05$ ), thereby justifying the use of ANCOVA. In contrast to our predictions, no day $\times$ test cue condition interaction was found $\left(\mathrm{F}_{1,29}=0.87, p=0.36\right)$, indicating that rats responded similarly to conditioned and novel stimuli during testing. An interaction between day and test cue modality was found $\left(F_{1,29}=7.52, p<0.05\right)$, where tests for simple effects of day revealed that rats tested with both cue modalities reinstated lever pressing compared with their extinction baseline (Figure 1c; ANOVAs, $p s<0.001$ ), but analysis of group effects on the test day revealed differences in the magnitude of reinstatement where rats tested with a light had higher response rates than tone-tested rats $\left(\mathrm{F}_{1}, 31=7.65, p<0.01\right.$; Figure $\left.1 \mathrm{c}\right)$. No group differences were found during baseline $\left(F_{1}, 31=0.01, p=0.99\right)$. No interactions or main effects of responding on the active lever were observed for saline-yoked groups (Table 1).

Fos immunoreactivity. Rats in the cocaine groups exhibited significantly more Fos-immunoreactive nuclei than rats in the saline-yoked groups in all of the brain regions analyzed, with the exception of the VTA (Table 2). This enhancement was evident as a significant main effect of drug history in the $\mathrm{dmCPu}, \mathrm{dlCPu}, \mathrm{NAcC}, \mathrm{NAcS}$, and $\mathrm{BlA}$ (Figure 2d; ranged from $\mathrm{F}_{1,45}=7.20$ to 18.09 , $p s<0.05$ ). No other significant main effects or interactions were found in these regions, implying that Fos expression was enhanced in the cocaine-trained animals, regardless of cue conditioning or modality. In the $\mathrm{Cg} 1$ region of the anterior cingulate cortex, a significant main effect of drug history was also found $\left(F_{1,40}=9.45, p<0.01\right)$, as well as a significant drug history $\times$ test cue modality interaction $\left(\mathrm{F}_{1}, 40=4.32\right.$, $p<0.05)$. Subsequent ANOVAs for the two drug conditions revealed that saline-yoked control rats tested with a light cue expressed significantly more Fos-positive nuclei than the rats tested with a tone (Figure $2 \mathrm{e} ; \mathrm{F}_{1,16}=6.84, p<0.05$ ). No such difference was found in the cocaine-trained groups $\left(F_{1,32}=1.05, p=0.31\right)$. In the $\mathrm{Cg} 2$ region of the anterior
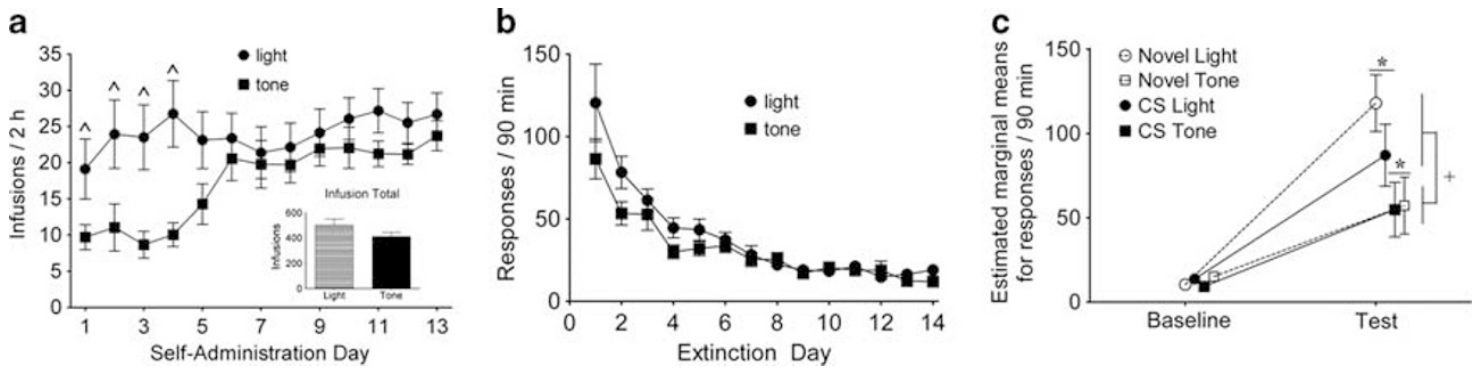

Figure I Cocaine reinforcement and seeking behavior from Experiment I. (a) Daily cocaine reinforcement rates (infusions \pm SEM) across sessions where infusions were paired with either a light (circles; $n=16$ ) or tone (squares; $n=18)$. Inset graph shows the total number of cocaine infusions $( \pm$ SEM) earned during self-administration. (b) Responses on the active lever ( \pm SEM) across extinction sessions in animals that had previously received either a light or tone cue paired with cocaine reinforcement during training; responses on the active lever produced no scheduled consequences during extinction. (c) Estimated marginal means for responses on the active lever/90 $\mathrm{min}( \pm \mathrm{SEM})$, with the change in inactive lever presses from baseline to test day as the covariate, for groups tested with novel (open symbols, dashed lines) or conditioned (closed symbols, solid lines) light (circles) or tone (squares) cues ( $n=7-9 / g r o u p)$. $\wedge$ Represents a significant difference from tone-trained group (tests of simple effects, $p<0.05$ ). *Represents a difference from baseline responding (ANOVA, $p<0.05$ ). ${ }^{+}$Represents a difference between test cue modalities (light vs tone; ANOVA, $p<0.05$ ). 
Table I Mean ( \pm SEM) Active and Inactive Lever Response Rates of Rats During Training, Extinction, and Reinstatement Test Sessions in Experiments I (Cocaine and Saline-Yoked), 2 (Sucrose), and 3 (Cues Only)

\begin{tabular}{|c|c|c|c|c|c|c|c|c|}
\hline \multirow[t]{3}{*}{ Reinforcer } & \multirow[t]{3}{*}{ Group $^{a}(n)$} & \multicolumn{2}{|c|}{$\begin{array}{l}\text { Responses/session }{ }^{\mathrm{b}} \text { during } \\
\text { the last } 5 \text { days of training }\end{array}$} & \multicolumn{3}{|c|}{$\begin{array}{l}\text { Responses/session } \\
\text { during extinction }\end{array}$} & \multicolumn{2}{|c|}{$\begin{array}{l}\text { Responses/session } \\
\text { on test day }\end{array}$} \\
\hline & & \multirow{2}{*}{$\begin{array}{l}\text { Active } \\
\text { lever }\end{array}$} & \multirow{2}{*}{$\begin{array}{l}\text { Inactive } \\
\text { lever }\end{array}$} & \multirow{2}{*}{$\begin{array}{c}\text { First day } \\
\begin{array}{c}\text { Inactive } \\
\text { lever }\end{array}\end{array}$} & \multicolumn{2}{|c|}{ Last day } & \multirow{2}{*}{$\begin{array}{l}\text { Active } \\
\text { lever }\end{array}$} & \multirow{2}{*}{$\begin{array}{l}\text { Inactive } \\
\text { lever }\end{array}$} \\
\hline & & & & & $\begin{array}{l}\text { Active } \\
\text { lever }\end{array}$ & $\begin{array}{l}\text { Inactive } \\
\text { lever }\end{array}$ & & \\
\hline \multirow{3}{*}{ Cocaine } & L-T (9) & $343 \pm 171.2$ & $6 \pm 4.7$ & $25 \pm 6.0$ & $16 \pm 1.9$ & $17 \pm 7.9$ & $51 \pm 9.5$ & $10 \pm 4.4$ \\
\hline & Т-Т (9) & $213 \pm 64.0$ & $158 \pm 155.3$ & $20 \pm 7.1$ & $9 \pm 1.4$ & $8 \pm 1.7$ & $55 \pm 9.5$ & $9 \pm 2.6$ \\
\hline & T-L (9) & $270 \pm 113.6$ & $147 \pm 100.3$ & $31 \pm 11.0$ & $10 \pm 1.9$ & $14 \pm 5.8$ & $124 \pm 23.9$ & $22 \pm 8.7$ \\
\hline \multirow[t]{2}{*}{ Saline-yoked } & L-L (4) & $4 \pm 1.8$ & $4 \pm 3.4$ & $4 \pm 2.2$ & $6 \pm 3.5$ & $3 \pm 1.1$ & $3 \pm 1.2$ & $3 \pm 1.3$ \\
\hline & L-T (3) & $9 \pm 6.9$ & $10 \pm 6.5$ & $4 \pm 0.9$ & $8 \pm 5.7$ & $12 \pm 7.3$ & $8 \pm 4.1$ & $10 \pm 3.2$ \\
\hline \multirow{2}{*}{ Sucrose } & T-Т (9) & $256 \pm 30.8$ & $5 \pm 1.0$ & $7 \pm 1.8$ & $14 \pm 3.8$ & $8 \pm 2.7$ & $60 \pm 9.0$ & $6 \pm 1.5$ \\
\hline & T-L (9) & $182 \pm 17.4$ & $10 \pm 2.3$ & $15 \pm 3.8$ & $6 \pm 1.2$ & $7 \pm 2.3$ & $76 \pm 13.3$ & $12 \pm 4.1$ \\
\hline \multirow[t]{4}{*}{ Cue only } & L-L (9) & $13 \pm 3.8$ & $6 \pm 2.1$ & $3 \pm 0.8$ & $6 \pm 1.0$ & $5 \pm 1.6$ & $7 \pm 2.5$ & $4 \pm 1.3$ \\
\hline & L-T (8) & $14 \pm 3.3$ & $4 \pm 0.9$ & $4 \pm 1.1$ & $7 \pm 2.0$ & $4 \pm 1.4$ & $1 \mid \pm 3.3$ & $3.0 \pm 1.1$ \\
\hline & Т-Т (9) & $6 \pm 0.7$ & $4 \pm 0.7$ & $4 \pm 0.9$ & $5 \pm 1.1$ & $5 \pm 1.8$ & $4 \pm 1.0$ & $2 \pm 0.5$ \\
\hline & T-L (8) & $5 \pm 0.8$ & $7 \pm 1.6$ & $4 \pm 1.4$ & $5 \pm 1.6$ & $6 \pm 1.7$ & $30 \pm 9.6$ & $10 \pm 2.2$ \\
\hline
\end{tabular}

a Light $(L)$ or tone $(T)$ training cue-test cue.

bession length varied depending on reinforcer (cocaine/saline: training, $2 \mathrm{~h}$; extinction/test, $90 \mathrm{~min}$; sucrose/cue only: training/extinction/test, 30 min).

Table 2 Mean ( \pm SEM) Number of Fos-Positive Nuclei for Each Region in Experiment I

\begin{tabular}{|c|c|c|c|c|c|c|c|c|c|}
\hline \multirow{2}{*}{ Reinforcer } & \multirow{2}{*}{ Group $^{a}(n)$} & \multicolumn{8}{|c|}{ Brain region $^{b}$} \\
\hline & & CgI & Cg2 & $\operatorname{dmCPu}$ & dICPu & NAcC & NAcS & BIA & VTA \\
\hline & L-T (9) & $15 \pm 3.8$ & $52 \pm 7.8$ & $7 \pm 1.4$ & $15 \pm 3.8$ & $54 \pm 8.8$ & $33 \pm 5.9$ & $8 \pm 1.5$ & $59 \pm 10.1$ \\
\hline & $\mathrm{T}-\mathrm{T}(9)$ & $25 \pm 4.9$ & $67 \pm 10.5$ & $12 \pm 2.3$ & $21 \pm 4.7$ & $67 \pm 12.3$ & $39 \pm 9.1$ & $11 \pm 1.6$ & $55 \pm 10.9$ \\
\hline & L-T (3) & $3 \pm 0.8$ & $28 \pm 8.3$ & $5 \pm 2.7$ & $8 \pm 3.1$ & $15 \pm 3.7$ & $9 \pm 2.1$ & $3 \pm 1.1$ & $47 \pm 11.6$ \\
\hline & T-T (4) & $4 \pm 1.6$ & $24 \pm 12.9$ & $2 \pm 2.1$ & $5 \pm 1.3$ & $20 \pm 12.5$ & $23 \pm 4.6$ & $5 \pm 2.3$ & $35 \pm 0.0$ \\
\hline & T-L (5) & $16 \pm 4.6$ & $38 \pm 11.1$ & $7 \pm 1.5$ & $8 \pm 1.4$ & $38 \pm 7.8$ & $16 \pm 2.4$ & $6 \pm 1.9$ & $24 \pm 9.3$ \\
\hline
\end{tabular}

a Light $(L)$ or tone $(T)$ training cue-test cue.

${ }^{\mathrm{b}}$ Abbreviations are described in the Methods (Fos Immunoreactivity Analysis) section.

cingulate cortex, a significant main effect of drug history was also found (Figure $2 \mathrm{~d} ; \mathrm{F}_{1,40}=9.33, p<0.01$ ), as well as a significant drug history $\times$ test cue condition $\times$ test cue modality interaction $\left(F_{1}, 40=4.32, p<0.05\right)$. Subsequent ANOVAs for the two drug conditions revealed a test cue condition $\times$ test cue modality interaction in the cocaineexposed rats $\left(\mathrm{F}_{1,28}=7.14, p<0.05\right)$, where post hoc analyses revealed a trend toward a higher number of Fos-positive nuclei in the novel light compared with the CS light group (Table 2; Tukey, $p=0.09$ ), which likely contributed to the interaction. No interactions or main effects were found in the $\mathrm{Cg} 2$ of the saline-yoked animals.

Correlations were also conducted within the cocaine groups separately for the novel vs CS test cue conditions to determine whether Fos expression in certain regions was related to the magnitude of responses on the active lever during testing. Interestingly, a positive correlation was found in the $\mathrm{dmCPu}$ for the novel (Figure 2f; $\mathrm{r}=0.70, p<0.01$ ), but not the CS (Figure $2 \mathrm{~g} ; \mathrm{r}=0.12$, $\mathrm{p}=0.67)$ test cue condition, indicating that the higher 

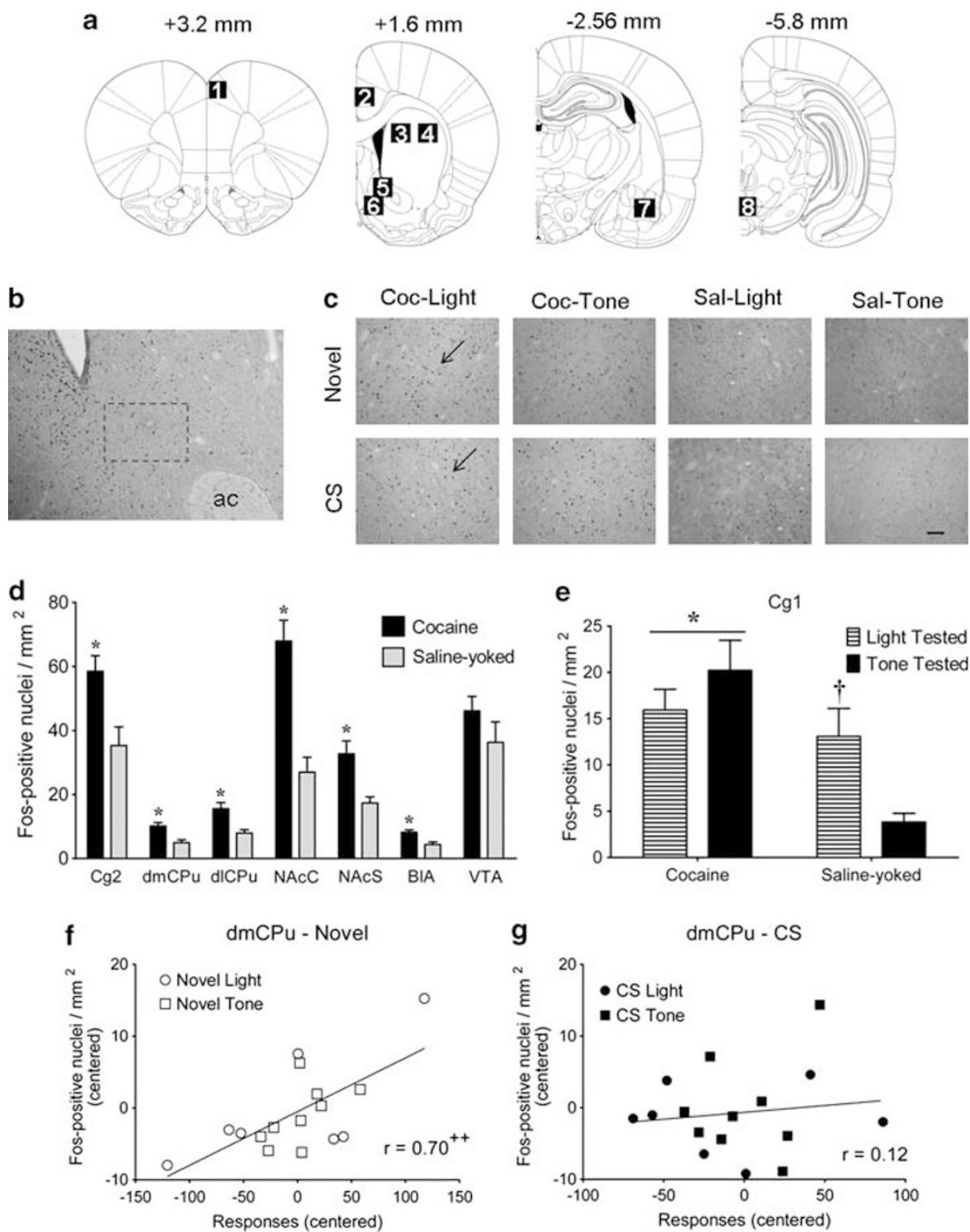

Figure 2 Fos protein expression data from Experiment I. (a) Schematic representations illustrating the regions analyzed in brain sections taken at +3.2 , $+1.6,-2.56$, and $-5.8 \mathrm{~mm}$ from bregma (Paxinos and Watson, 1998). The numbered regions are as follows: (I) CgI region of the anterior cingulate cortex (CgI); (2) Cg2 region of the anterior cingulate cortex (Cg2); (3) dorsomedial caudate/putamen (dmCPu); (4) dorsolateral caudate/putamen (dlCPu); (5) nucleus accumbens core (NAcC); (6) nucleus accumbens shell (NAcS); (7) basolateral amygdala (BIA); and (8) ventral tegmental area (VTA).

(b) Representative photomicrographs at $\times 10$ magnification of Fos protein expression in the NAcC with a dashed rectangle indicating the sample region. (c) NAcC samples taken at $\times 20$ magnification from a representative subject/group with arrows indicating Fos-positive nuclei. All sample areas were $0.26 \mathrm{~mm}^{2}$ and all photomicrographs were taken at $\times 20$ magnification with the scale bar equal to $100 \mu \mathrm{m}$. (d) Number of Fos-positive nuclei/mm ${ }^{2}$ ( \pm SEM) in brain regions that exhibited enhanced Fos expression in rats with a history of cocaine self-administration $(n=32)$ compared with saline controls $(n=16)$ in Experiment I. Data are grouped by drug history. (e) Fos expression ( \pm SEM) in the CgI grouped by drug history and test cue modality ( $n=7-\mid 8 / g r o u p)$. Scatter plot of dmCPu for the cocaine $(f)$ novel $(n=15)$ and $(g)$ the CS $(n=16)$ test cue groups with Fos expression vs test session cocaine-seeking behavior. Fos-positive nuclei/mm $\mathrm{mm}^{2}$ and test session responding on the active lever were centered to where ' 0 ' represents the mean of each test cue modality in order to remove group differences. The line represents a best-fit linear relationship between the two variables. *Represents a difference from saline-yoked groups $(p<0.05)$. 'Represents a difference from the saline tone-tested group (ANOVA, $p<0.05) .{ }^{++}$Represents a positive linear correlation among responding on the active lever and Fos-labeled cells $(p<0.0 \mathrm{I})$. ac, anterior commissure.

responding on the active lever when tested with a novel cue the higher the expression of Fos in the dmCPu. No other significant correlations were found in the remaining brain regions.

\section{Experiment 2}

Sucrose reinforcement training. The 15 light-trained sucrose rats received a total of $382 \pm 33$ sucrose pellets and the 18 tone-trained sucrose rats received a total of $412 \pm 22$ sucrose pellets during training. A significant interaction between session and training cue was found $\left(\mathrm{F}_{5}, 154=2.38, p<0.05\right)$, where tests for simple effects of group revealed that the tone-trained rats exhibited higher reinforcement rates relative to light-trained rats during the transition from mild food restriction to ad libitum access, specifically on days 7 and 8 (Figure 3a; ANOVAs, 

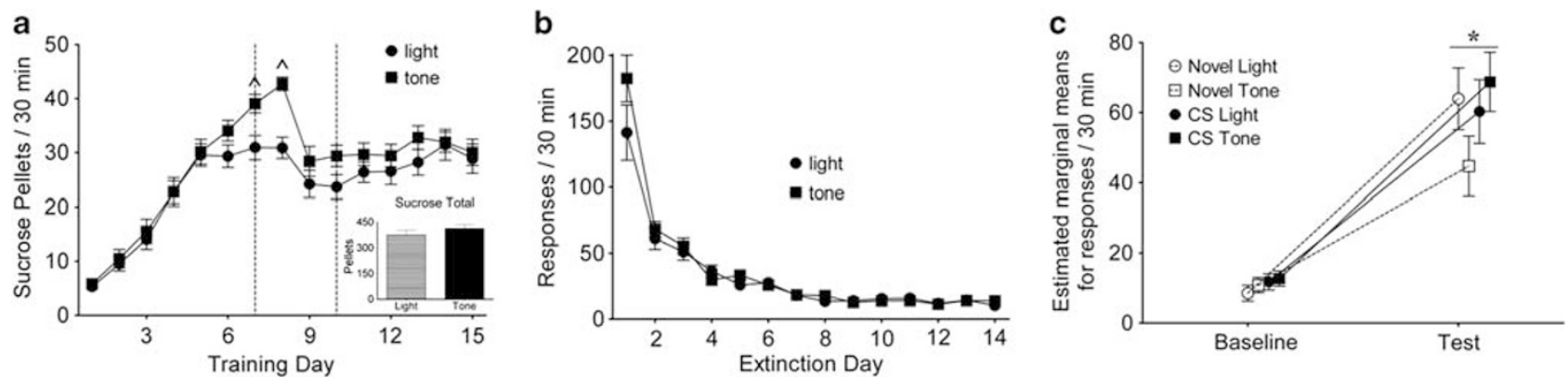

Figure 3 Sucrose reinforcement and seeking behavior from Experiment 2. (a) Daily reinforcement rates ( \pm SEM) for rats trained to lever press for sucrose pellets that were paired with a light (circles) or a tone (squares). Inset graph shows the total number of sucrose pellets ( \pm SEM) attained across all training sessions. Dashed vertical lines represent the transition period from food restriction ( 16-22g chow/day) to food ab libitium. (b) Responses on the active lever $( \pm$ SEM) across extinction sessions in animals that had previously received either a light or a tone cue paired with sucrose reinforcement during training; responses on the active lever produced no scheduled consequences during extinction. (c) Estimated marginal means for responses on the active lever/30 min ( \pm SEM), with the change in inactive lever presses from baseline to test day as the covariate, for groups tested with novel (open symbols, dashed lines) or conditioned (closed symbols, solid lines) light (circles) or tone (squares) cues $(n=7-9 / g r o u p)$. ${ }^{\wedge}$ Represents a difference from the lighttrained group (tests of simple effects, $p<0.05)$. *Represents a difference from baseline responding $(p<0.05)$.

$p<0.05)$. Overall, there was no group difference in the total number of pellets received across all training sessions (Figure $3 \mathrm{a}$ inset; $\mathrm{F}_{1,31}=2.48, p=0.13$ ).

Extinction and reinstatement of sucrose-seeking behavior. Responses on the active lever reduced across extinction training (Figure $3 \mathrm{~b}$ ), where a main effect of session was found $\left(F_{2}, 56=92.13, p<0.001\right)$, and there were no group differences in response rates. Post hoc analyses revealed that last-day extinction lever presses were significantly reduced from first-day extinction lever presses (Bonferroni correction, $p<0.05)$. No significant changes were found during extinction for responding on the inactive lever (Table 1).

To assess reinstatement of sucrose-seeking behavior, we compared responses on the active lever during testing with responses on the active lever during the last extinction session, with day as a within-subjects factor and test cue condition and test cue modality as between-subjects factors. As with Experiment 1, the use of the covariate (change in inactive lever presses from baseline to test day) was justified as there were no interactions with test-day condition and/or modality (ranged from $\mathrm{F}_{1,28}=0.03$ to $1.97, p \mathrm{~s}>0.05$ ). Only a main effect for day was found for active lever presses $\left(\mathrm{F}_{1,28}=123.14, p<0.001\right)$, indicating that test-day responding increased compared with extinction baseline regardless of other factors (Figure 3c).

\section{Experiment 3}

Cue reinforcement training. Across training, the 18 light cue-trained rats received a total of $65 \pm 7$ light presentations and the 18 tone cue-trained sucrose rats received a total of $46 \pm 3$ tone presentations. No interaction between session and training cue was found (Figure 4a; $F_{14}, 448=0.94$, $p=0.52$ ), but the light cue group received more cue presentations than the tone cue group overall (Figure $4 \mathrm{a}$ inset; $\mathrm{F}_{1,32}=5.73, p<0.05$ ).

Extinction and test day responding for the cue-only condition. A significant interaction between session and training cue was found $\left(\mathrm{F}_{6.0}, 192.8=3.16, p<0.01\right)$, where tests of simple effects of group revealed that the light-trained group had higher responding on the active lever than the tone-trained group on several days throughout extinction (Figure $4 \mathrm{~b}$; ANOVAs, $p s<0.05$ ). Post $h o c$ analyses revealed that last-day extinction lever presses were significantly reduced from first-day extinction lever presses in the light-trained group (Bonferroni correction; $p<0.025)$, but not in the tone-trained group. No significant changes were observed during extinction for responses on the inactive lever (Table 1).

We analyzed test-day responding for cues the same as Experiments 1 and 2, as well as the use of the covariate, which was justified as no interaction existed with test cue condition and/or modality (range from $\mathrm{F}_{1,29}=0.40$ to 2.88 , $p s>0.05)$. Surprisingly, analysis of the cue-only condition reinstatement data revealed a significant interaction between day and test cue condition $\left(\mathrm{F}_{1,29}=5.22, p<0.05\right)$, where tests for simple effects of day revealed that the novel test cue condition exhibited increased responding on the active lever on test day compared with baseline (Figure 4c; $\left.\mathrm{F}_{1,14}=6.32, p<0.05\right)$, whereas no such effect was found in the CS test cue condition $\left(\mathrm{F}_{1,16}=0.08, p=0.78\right)$. Analysis of group effects during test day revealed a trend where the novel cue groups responded higher than the CS groups $\left(\mathrm{F}_{1,31}=3.53, p=0.07\right)$, and no difference was found during baseline responding $\left(\mathrm{F}_{1,31}=0.31, p=0.58\right)$.

\section{DISCUSSION}

The aim of this study was to use a novel cue control group to parse out the contribution of experiencing novelty during cue reinstatement testing to Fos expression. On cue reinstatement test days, animals experience novelty in receiving a response-contingent stimulus (that is, CS+) following a prolonged period of non-reinforced responding. Given that Fos expression is sensitive to environmental and procedural novelty (Badiani et al, 1998; Handa et al, 1993), we compared expression in animals exposed with drugpaired $v s$ novel stimuli predicting that there would be greater Fos and perhaps region-specific activation owing to drug-conditioning. Surprisingly, novel cues elicited similar reinstatement behavior and Fos expression patterns as 

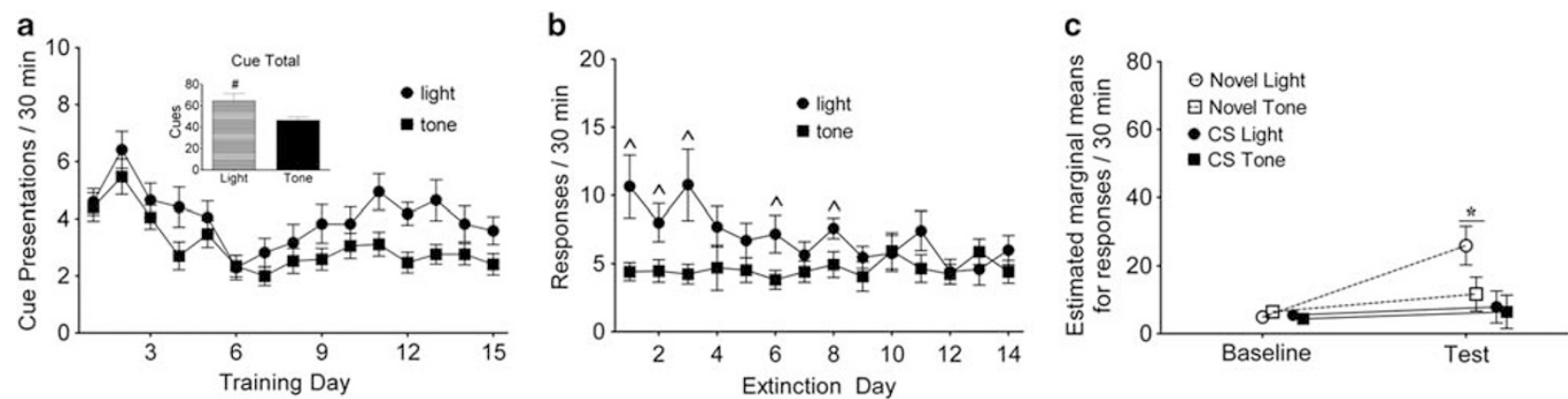

Figure 4 Cue reinforcement and seeking behavior from Experiment 3. (a) Daily reinforcement rates ( \pm SEM) for rats trained to lever press for either a light (circles) or a tone (squares) cue presentation. Inset graph shows the total number of cue presentations ( \pm SEM) earned across all training sessions. (b) Responses on the active lever ( \pm SEM) across extinction sessions in animals that had previously received either a light or a tone cue without reinforcement during training; responses on the active lever produced no scheduled consequences during extinction. (c) Estimated marginal means for responses on the active lever/30 min ( \pm SEM), with the change in inactive lever presses from baseline to test day as the covariate, for groups tested with novel (open symbols, dashed lines) or conditioned (closed symbols, solid lines) light (circles) or tone (squares) cues ( $n=8-9 / g r o u p) ~ \#$ Represents a difference from the tone-trained group in total number of cue presentations $(p<0.05)$. ^ Represents a difference from the tone-trained group (tests for simple effects, $p<0.05$ ). *Represents a difference from baseline responding (tests of simple effects, $p<0.05$ ).

conditioned stimuli. We then hypothesized that cocaine SA may have cross-sensitized reinforcement circuits to novelty, which acts on converging reward pathways (Bardo et al, 1996; Besheer et al, 1999). To address this question, we examined whether novel cues reinstated sucrose-seeking behavior using parameters that are not consistent with sensitizing effects from sucrose reinforcement (Avena et al, 2005). Nevertheless, a similar outcome occurred where all sucrose groups reinstated regardless of whether they received CS + or novel cues. These findings suggested that drug-specific sensitization was not a likely explanation, and instead novel cues had similar effects on drug and non-drug reinforcement-seeking behavior. We considered three possible explanations for the novel cue reinstatement effect that are stated below.

\section{Novelty Reinforcement}

The rewarding properties of novelty have been documented in humans and animals (Bardo et al, 1989, 1996; Besheer et al, 1999), and motivation for novelty predicts individual sensitivity to drug reward and reinforcement (Belin et al, 2011; Davis et al, 2008; Nadal et al, 2002; Pelloux et al, 2006; Piazza et al, 1989, 2000; Suto et al, 2001). We therefore suggest that the novel stimuli may have activated similar reinforcement and motivation processes as those involved in conditioned reinforcement-seeking behavior. In support, the Fos expression resulting from novel cue reinforcement was highly similar to that found previously during $\mathrm{CS}+$ re-exposure (Kufahl et al, 2009; Neisewander et al, 2000). The latter study also used a no-lever control group and found similar activation, suggesting that our findings are not due to the act of operant responding, but instead likely reflect circuits that have a role in drug motivational processes invoked for expression of cocaine-seeking behavior (Fuchs et al, 2002, 2004, 2006; Ito et al, 2004; Kalivas and McFarland, 2003; Kruzich and See, 2001b). Reinstatement observed under the cue-only condition further supports the reinforcing effects of the response-contingent novel stimuli (Baron and Kish, 1962).

We also considered the stress-provoking effects of novel stimuli and procedures that occur in rodents (Kabbaj et al, 2000; Piazza et al, 1991; Rozin and Kalat, 1971). Stress is known to facilitate both drug reinforcement and incentive motivation, where various stressors have the ability to reinstate drug and sucrose-seeking behavior (Bossert et al, 2005; Shaham et al, 2003; Simms et al, 2011). Novel stimuli have the tendency to induce both approach and avoidance in animals, and it is the balance between these two conflicting motivations that drive subsequent behavior (Montgomery and Monkman, 1955). Although exposure to discrete novel cues in our study may have induced an initial stress response, the animals appeared to approach, rather than avoid, making responses to receive cue presentations. This suggests that potential stress effects of the novel cues likely facilitated, rather than inhibited, the animal's motivation to seek reinforcement.

It is possible that novel and conditioned stimuli may produce similar levels of reinstatement, but by differentially engaging reward (that is, liking) $v$ s incentive salience (that is, wanting) systems. Robinson and Berridge's (1993) theory of incentive sensitization posits that these systems are dissociable and that incentive salience of drug and drug-associated cues sensitizes, whereas the hedonic value of the drug either decreases or remains stable over time. In our experiment, conditioned cues may trigger sensitized motivational circuits with little influence from hedonic value, resulting in reinstatement of drug-seeking behavior. By contrast, the novel cue may first engage hedonic processes, as the increase in responding in the cue-only condition suggests. Activation of reward processes within the drug-associated context may then activate the sensitized motivational circuits, resulting in robust novel cue-seeking behavior. Thus, on the test day the novel and conditioned stimuli may be activating the same sensitized motivational circuit that developed during training, resulting in similar reinstatement effects.

\section{Activation of Action-Outcome Habits}

Beyond the stimulating effects of the novel cue, a history of reinforcement paired with response-contingent stimuli likely induced a strong action-outcome habit that the 
response-contingent novel cue re-engaged during testing. Prolonged appetitive training is known to initially show goal-directed behavior and then transition to habitual responding (Jog et al, 1999), and contingent cues likely facilitated this transition in our study, as well as initial acquisition (Deroche-Gamonet et al, 2002). Kruzich et al (2001a) found that a novel light/tone combination failed to produce reinstatement in animals that had no cocainepaired cues during training, suggesting that reinforcement experience alone is insufficient for novel cue reinstatement. Thus, novel cues are able to reinforce responding reliably only when they are presented similarly to conditioned stimuli, thereby initiating habits that are resistant to stimulus modality changes.

The positive correlation between the degree of Fos expression in the $\mathrm{dmCPu}$ and responding for novel, but not $\mathrm{CS}+$, cues is an interesting finding that is consistent with previous research demonstrating a similar regionspecific effect in high novelty-seeking animals (that is, high responders; Kabbaj and Akil, 2001). The cause of this relationship is unclear, but projections from the visual/ auditory cortices to the dmCPu (McGeorge and Faull, 1989) may be involved as the sensory properties of novel stimuli are salient upon their first presentation. Our reinstatement data support this claim, where cue modality had a greater effect on responding in the novel $v s$ conditioned cue groups. The $\mathrm{dmCPu}$ has been implicated in behavioral flexibility and attention, where neurons in this region fire in response to environmental changes during a spatial working memory task and regional inactivation has been shown to impair performance of a visually signaled time-dependent response task (Mizumori et al, 2000; Ragozzino et al, 2002). The greater degree of change to the environment in the novel, compared with the CS, test cue condition may differentially engage the $\mathrm{dmCPu}$ reflective of the amount of attention given to the stimulus.

While novel and conditioned cues elicited similar seeking behavior and brain activation, response magnitude and Fos effects varied in some cases with stimulus modality. Others have reported an impact of cue modality on responding, where a light cue is capable of eliciting greater responding than a tone cue (Baron and Kish, 1962; Di Ciano and Everitt, 2003; Panlilio and Schindler, 1997; Reed et al, 1996; See et al, 1999). We found that a light was more effective than a tone during cocaine SA and reinstatement, as well as during training in the cue-only condition. The light cue also induced greater Fos expression in the Cg1 of the saline controls compared with the tone, which may be due to attention because this region is engaged in the presence of salient stimuli (Downar et al, 2002). By contrast, the tone cue appeared to elicit slightly greater responding during sucrose training. These findings are curious, but this difference could be due to the ability of psychostimulants to increase responding for visual stimuli (Caggiula et al, 2002; Deroche-Gamonet et al, 2002; Donny et al, 2003; Gancarz et al, 2011; Palmatier et al, 2006; Winterbauer and Balleine, 2007) and amplify sensitivity to acoustic stimuli (Davis, 1985; Davis et al, 1975), thereby enhancing the initial reinforcing and/or aversive properties of the light and tone cues, respectively (Baron and Kish, 1962). Regardless, our cue modality effects are consistent with the sensory reinforcement literature.

\section{Contextual Effects}

Our procedure of testing in the original training context may also contribute to responding for novel stimuli during the test session by reigniting the incentive motivational value of the reinforcement context. It is well established that contextual manipulations exert control over operant responding, where reinforcement seeking and other conditioned responses are reinstated by exposure to the training context following a period of prolonged abstinence or extinction in a different context (Bouton and Peck, 1989; Crombag and Shaham, 2002; Neisewander et al, 2000). By contrast, exposing rats to a novel context during testing (that is, an AAB procedure) does not reinstate drug-seeking (Bossert et al, 2004; Crombag and Shaham, 2002; Fuchs et al, 2005), or conditioned responses (Bouton and King, 1983), highlighting the unique impact of the original training context on responding. Furthermore, midbrain dopamine neurons fire in response to conditioned stimuli predictive of reward as well as unfamiliar, but similar stimuli when presented in the same context (Schultz, 1998). The incentive motivational value of the context may be necessary to achieve heightened novel cue responding, perhaps through the training environment acting as discriminative stimuli or an 'occasion setter' (Alleweireldt et al, 2001; Swartzentruber, 1991). The importance of contextual contributions to novel cue reinstatement of drug-seeking behavior will require further attention.

\section{Conclusions}

The present study has uncovered novel information that calls for additional thought about how reinstatement of reinforcement-seeking behavior is mediated. It appears that in a reinforcement-associated context, novelty can trigger incentive motivation similar to that of conditioned stimuli. Furthermore, the neural circuitry involved in reinstatement by both types of cues largely overlaps. We have suggested potential mechanisms, which are not mutually exclusive, that may mediate, or contribute at least in part, to novel cue reinstatement. These include: (1) novel stimulus-elicited activation of brain reinforcement mechanisms that in turn drive reinforcement-seeking behavior similar to $\mathrm{CS}+$ stimuli; (2) response-contingent events re-engaging action-outcome processes that have become habitual; and (3) the ability of novelty or CS + reinforcement to reinstate the incentive motivational effects of the reward-associated context. In terms of drug abuse and other addictive behaviors, the present findings suggest novel potential mechanisms by which environmental stimuli may disrupt abstinence as effectively as stimuli known to be associated with reinforcement. Further understanding of how novelty relates to craving for drugs of abuse or food reinforcers is important for understanding relapse and for future therapeutic interventions.

\section{ACKNOWLEDGEMENTS}

This work was supported by NIDA grants DA11064 and DA 021485. We thank Timothy Cheung, Natalie Peartree, Lara Pockros, Tom Shepherd, Krista Heintzelman, Claudia Vargas, Lauren Hood, Stephanie Kost, and Katie Olsen for 
technical contributions and Dr Joshua Talboom for his advice with statistics.

\section{DISCLOSURE}

JN has received honoraria for seminar presentations given at the conference of the Association for Behavioral Analysis International, the University of Texas Health Sciences Center at San Antonio, Oregon Health and Sciences University, University of North Carolina-Chapel Hill, and Florida State University. The authors declare no conflict of interest.

\section{REFERENCES}

Alleweireldt AT, Weber SM, Neisewander JL (2001). Passive exposure to a contextual discriminative stimulus reinstates cocaine-seeking behavior in rats. Pharmacol Biochem Behav 69: 555-560.

Avena NM, Long KA, Hoebel BG (2005). Sugar-dependent rats show enhanced responding for sugar after abstinence: evidence of a sugar deprivation effect. Physiol Behav 84: 359-362.

Badiani A, Oates MM, Day HE, Watson SJ, Akil H, Robinson TE (1998). Amphetamine-induced behavior, dopamine release, and c-fos mRNA expression: modulation by environmental novelty. J Neurosci 18: 10579-10593.

Bardo MT, Donohew RL, Harrington NG (1996). Psychobiology of novelty seeking and drug seeking behavior. Behav Brain Res 77: 23-43.

Bardo MT, Neisewander JL, Pierce RC (1989). Novelty-induced place preference behavior in rats: effects of opiate and dopaminergic drugs. Pharmacol Biochem Behav 32: 683-689.

Baron A, Kish GB (1962). Low-intensity auditory and visual stimuli as reinforcers for the mouse. J Comp Physiol Psychol 55: 1011-1013.

Belin D, Berson N, Balado E, Piazza PV, Deroche-Gamonet V (2011). High-novelty-preference rats are predisposed to compulsive cocaine self-administration. Neuropsychopharmacology 36: 569-579.

Besheer J, Jensen HC, Bevins RA (1999). Dopamine antagonism in a novel-object recognition and a novel-object place conditioning preparation with rats. Behav Brain Res 103: 35-44.

Bizo LA, Bogdanov SV, Killeen PR (1998). Satiation causes withinsession decreases in instrumental responding. J Exp Psychol Anim Behav Process 24: 439-452.

Bossert JM, Ghitza UE, Lu L, Epstein DH, Shaham Y (2005). Neurobiology of relapse to heroin and cocaine seeking: an update and clinical implications. Eur J Pharmacol 526: 36-50.

Bossert JM, Liu SY, Lu L, Shaham Y (2004). A role of ventral tegmental area glutamate in contextual cue-induced relapse to heroin seeking. J Neurosci 24: 10726-10730.

Bouton ME, King DA (1983). Contextual control of the extinction of conditioned fear: tests for the associative value of the context. J Exp Psychol Anim Behav Process 9: 248-265.

Bouton ME, Peck CA (1989). Context effects on conditioning, extinction, and reinstatement in an appetitive conditioning preparation. Anim Learn Behav 17: 188-198.

Brown EE, Robertson GS, Fibiger HC (1992). Evidence for conditional neuronal activation following exposure to a cocaine-paired environment: role of forebrain limbic structures. J Neurosci 12: 4112-4121.

Caggiula AR, Donny EC, White AR, Chaudhri N, Booth S, Gharib MA et al (2002). Environmental stimuli promote the acquisition of nicotine self-administration in rats. Psychopharmacology (Berl) 163: 230-237.

Carroll ME, France CP, Meisch RA (1981). Intravenous selfadministration of etonitazene, cocaine and phencyclidine in rats during food deprivation and satiation. J Pharmacol Exp Ther 217: 241-247.

Chaudhuri A (1997). Neural activity mapping with inducible transcription factors. Neuroreport 8: v-ix.

Childress A, Ehrman R, McLellan AT, O’Brien C (1988). Conditioned craving and arousal in cocaine addiction: a preliminary report. NIDA Res Monogr 81: 74-80.

Childress AR, Mozley PD, McElgin W, Fitzgerald J, Reivich M, O'Brien CP (1999). Limbic activation during cue-induced cocaine craving. Am J Psychiatry 156: 11-18.

Ciccocioppo R, Sanna PP, Weiss F (2001). Cocaine-predictive stimulus induces drug-seeking behavior and neural activation in limbic brain regions after multiple months of abstinence: reversal by $\mathrm{D}(1)$ antagonists. Proc Natl Acad Sci USA 98: 1976-1981.

Clark JD, Gebhart GF, Gonder JC, Keeling ME, Kohn DF (1997). Special report: the 1996 guide for the care and use of laboratory animals. ILAR J 38: 41-48.

Crawford CA, McDougall SA, Bolanos CA, Hall S, Berger SP (1995). The effects of the kappa agonist U-50,488 on cocaine-induced conditioned and unconditioned behaviors and Fos immunoreactivity. Psychopharmacology (Berl) 120: 392-399.

Crombag HS, Shaham Y (2002). Renewal of drug seeking by contextual cues after prolonged extinction in rats. Behav Neurosci 116: 169-173.

Curran T, Morgan JI (1995). Fos: an immediate-early transcription factor in neurons. J Neurobiol 26: 403-412.

Davis BA, Clinton SM, Akil H, Becker JB (2008). The effects of novelty-seeking phenotypes and sex differences on acquisition of cocaine self-administration in selectively bred High-Responder and Low-Responder rats. Pharmacol Biochem Behav 90: 331-338.

Davis M (1985). Cocaine: excitatory effects on sensorimotor reactivity measured with acoustic startle. Psychopharmacology (Berl) 86: 31-36.

Davis M, Svensson TH, Aghajanian GK (1975). Effects of d- and 1amphetamine on habituation and sensitization of the acoustic startle response in rats. Psychopharmacologia 43: 1-11.

Deroche-Gamonet V, Piat F, Le Moal M, Piazza PV (2002). Influence of cue-conditioning on acquisition, maintenance and relapse of cocaine intravenous self-administration. Eur $J$ Neurosci 15: 1363-1370.

Di Ciano P, Everitt BJ (2003). Differential control over drugseeking behavior by drug-associated conditioned reinforcers and discriminative stimuli predictive of drug availability. Behav Neurosci 117: 952-960.

Donny EC, Chaudhri N, Caggiula AR, Evans-Martin FF, Booth S, Gharib MA et al (2003). Operant responding for a visual reinforcer in rats is enhanced by noncontingent nicotine: implications for nicotine self-administration and reinforcement. Psychopharmacology (Berl) 169: 68-76.

Downar J, Crawley AP, Mikulis DJ, Davis KD (2002). A cortical network sensitive to stimulus salience in a neutral behavioral context across multiple sensory modalities. J Neurophysiol 87: 615-620.

Ehrman RN, Robbins SJ, Childress AR, O'Brien CP (1992). Conditioned responses to cocaine-related stimuli in cocaine abuse patients. Psychopharmacology (Berl) 107: 523-529.

Fuchs RA, Branham RK, See RE (2006). Different neural substrates mediate cocaine seeking after abstinence versus extinction training: a critical role for the dorsolateral caudate-putamen. J Neurosci 26: 3584-3588.

Fuchs RA, Evans KA, Ledford CC, Parker MP, Case JM, Mehta RH et al (2005). The role of the dorsomedial prefrontal cortex, basolateral amygdala, and dorsal hippocampus in contextual reinstatement of cocaine seeking in rats. Neuropsychopharmacology 30: 296-309. 
Fuchs RA, Evans KA, Parker MC, See RE (2004). Differential involvement of the core and shell subregions of the nucleus accumbens in conditioned cue-induced reinstatement of cocaine seeking in rats. Psychopharmacology (Berl) 176: 459-465.

Fuchs RA, Tran-Nguyen LT, Specio SE, Groff RS, Neisewander JL (1998). Predictive validity of the extinction/reinstatement model of drug craving. Psychopharmacology (Berl) 135: 151-160.

Fuchs RA, Weber SM, Rice HJ, Neisewander JL (2002). Effects of excitotoxic lesions of the basolateral amygdala on cocaineseeking behavior and cocaine conditioned place preference in rats. Brain Res 929: 15-25.

Gancarz AM, San George MA, Ashrafioun L, Richards JB (2011). Locomotor activity in a novel environment predicts both responding for a visual stimulus and self-administration of a low dose of methamphetamine in rats. Behav Process 86: 295-304.

Garavan H, Pankiewicz J, Bloom A, Cho JK, Sperry L, Ross TJ et al (2000). Cue-induced cocaine craving: neuroanatomical specificity for drug users and drug stimuli. Am J Psychiatry 157: 1789-1798.

Grant S, London ED, Newlin DB, Villemagne VL, Liu X, Contoreggi C et al (1996). Activation of memory circuits during cue-elicited cocaine craving. Proc Natl Acad Sci USA 93: 12040-12045.

Guo N, Garcia MM, Harlan RE (2008). A morphine-paired environment alters c-Fos expression in the forebrain of rats displaying conditioned place preference or aversion. Behav Neurosci 122: 1078-1086.

Handa RJ, Nunley KM, Bollnow MR (1993). Induction of c-fos mRNA in the brain and anterior pituitary gland by a novel environment. Neuroreport 4: 1079-1082.

Harlan RE, Garcia MM (1998). Drugs of abuse and immediateearly genes in the forebrain. Mol Neurobiol 16: 221-267.

Hotsenpiller G, Horak BT, Wolf ME (2002). Dissociation of conditioned locomotion and Fos induction in response to stimuli formerly paired with cocaine. Behav Neurosci 116: 634-645.

Ito R, Robbins TW, Everitt BJ (2004). Differential control over cocaine-seeking behavior by nucleus accumbens core and shell. Nat Neurosci 7: 389-397.

Jog MS, Kubota Y, Connolly CI, Hillegaart V, Graybiel AM (1999). Building neural representations of habits. Science 286: 1745-1749.

Kabbaj M, Akil H (2001). Individual differences in novelty-seeking behavior in rats: a c-fos study. Neuroscience 106: 535-545.

Kabbaj M, Devine DP, Savage VR, Akil H (2000). Neurobiological correlates of individual differences in novelty-seeking behavior in the rat: differential expression of stress-related molecules. J Neurosci 20: 6983-6988.

Kalivas PW, McFarland K (2003). Brain circuitry and the reinstatement of cocaine-seeking behavior. Psychopharmacology (Berl) 168: 44-56.

Kruzich PJ, Congleton KM, See RE (2001a). Conditioned reinstatement of drug-seeking behavior with a discrete compound stimulus classically conditioned with intravenous cocaine. Behav Neurosci 115: 1086-1092.

Kruzich PJ, See RE (2001b). Differential contributions of the basolateral and central amygdala in the acquisition and expression of conditioned relapse to cocaine-seeking behavior. J Neurosci 21: RC155.

Kufahl PR, Zavala AR, Singh A, Thiel KJ, Dickey ED, Joyce JN et al (2009). c-Fos expression associated with reinstatement of cocaine-seeking behavior by response-contingent conditioned cues. Synapse 63: 823-835.

Markou A, Weiss F, Gold LH, Caine SB, Schulteis G, Koob GF (1993). Animal models of drug craving. Psychopharmacology (Berl) 112: 163-182.

McGeorge AJ, Faull RL (1989). The organization of the projection from the cerebral cortex to the striatum in the rat. Neuroscience 29: $503-537$.
Miller CA, Marshall JF (2005). Molecular substrates for retrieval and reconsolidation of cocaine-associated contextual memory. Neuron 47: 873-884.

Mizumori SJ, Ragozzino KE, Cooper BG (2000). Location and head direction representation in the dorsal striatum of rats. Psychobiology 28: 441-462.

Montgomery KC, Monkman JA (1955). The relation between fear and exploratory behavior. J Comp Physiol Psychol 48: 132-136.

Moratalla R, Vickers EA, Robertson HA, Cochran BH, Graybiel AM (1993). Coordinate expression of c-fos and jun B is induced in the rat striatum by cocaine. J Neurosci 13: 423-433.

Nadal R, Armario A, Janak PH (2002). Positive relationship between activity in a novel environment and operant ethanol self-administration in rats. Psychopharmacology (Berl) 162: 333-338.

Neisewander JL, Baker DA, Fuchs RA, Tran-Nguyen LT, Palmer A, Marshall JF (2000). Fos protein expression and cocaine-seeking behavior in rats after exposure to a cocaine self-administration environment. J Neurosci 20: 798-805.

Palmatier MI, Evans-Martin FF, Hoffman A, Caggiula AR, Chaudhri N, Donny EC et al (2006). Dissociating the primary reinforcing and reinforcement-enhancing effects of nicotine using a rat self-administration paradigm with concurrently available drug and environmental reinforcers. Psychopharmacology (Berl) 184: 391-400.

Panlilio LV, Schindler CW (1997). Conditioned locomotoractivating and reinforcing effects of discrete stimuli paired with intraperitoneal cocaine. Behav Pharmacol 8: 691-698.

Paxinos G, Watson C (1998). The Rat Brain in Stereotaxic Coordinates. Academic Press: San Diego, CA.

Pelloux Y, Costentin J, Duterte-Boucher D (2006). Novelty preference predicts place preference conditioning to morphine and its oral consumption in rats. Pharmacol Biochem Behav 84: 43-50.

Piazza PV, Deminiere JM, Le Moal M, Simon H (1989). Factors that predict individual vulnerability to amphetamine self-administration. Science 245: 1511-1513.

Piazza PV, Deroche-Gamonent V, Rouge-Pont F, Le Moal M (2000). Vertical shifts in self-administration dose-response functions predict a drug-vulnerable phenotype predisposed to addiction. J Neurosci 20: 4226-4232.

Piazza PV, Maccari S, Deminiere JM, Le Moal M, Mormede P, Simon H (1991). Corticosterone levels determine individual vulnerability to amphetamine self-administration. Proc Natl Acad Sci USA 88: 2088-2092.

Ragozzino ME, Ragozzino KE, Mizumori SJ, Kesner RP (2002). Role of the dorsomedial striatum in behavioral flexibility for response and visual cue discrimination learning. Behav Neurosci 116: $105-115$.

Reed P, Mitchell C, Nokes T (1996). Intrinsic reinforcing properties of putatively neutral stimuli in an instrumental two-lever discrimination task. Anim Learn Behav 24: 38-45.

Robinson TE, Berridge KC (1993). The neural basis of drug craving: an incentive-sensitization theory of addiction. Brain Res Brain Res Rev 18: 247-291.

Rozin P, Kalat JW (1971). Specific hungers and poison avoidance as adaptive specializations of learning. Psychol Rev 78: 459-486.

Schultz W (1998). Predictive reward signal of dopamine neurons. J Neurophysiol 80: 1-27.

See RE, Grimm JW, Kruzich PJ, Rustay N (1999). The importance of a compound stimulus in conditioned drug-seeking behavior following one week of extinction from self-administered cocaine in rats. Drug Alcohol Depend 57: 41-49.

Shaham Y, Shalev U, Lu L, De Wit H, Stewart J (2003). The reinstatement model of drug relapse: history, methodology and major findings. Psychopharmacology (Berl) 168: 3-20.

Simms JA, Richards JK, Mill D, Kanholm I, Holgate JY, Bartlett SE (2011). Induction of multiple reinstatements of ethanol- and 
sucrose-seeking behavior in Long-Evans rats by the alpha-2 adrenoreceptor antagonist yohimbine. Psychopharmacology (Berl) 218: 101-110.

Stewart J (1983). Conditioned and unconditioned drug effects in relapse to opiate and stimulant drug self-adminstration. Prog Neuropsychopharmacol Biol Psychiatry 7: 591-597.

Suto N, Austin JD, Vezina P (2001). Locomotor response to novelty predicts a rat's propensity to self-administer nicotine. Psychopharmacology (Berl) 158: 175-180.

Swartzentruber D (1991). Blocking between occasion setters and contextual stimuli. J Exp Psychol Anim Behav Process 17: 163-173.

Thiel KJ, Pentkowski NS, Peartree NA, Painter MR, Neisewander JL (2010). Environmental living conditions introduced during forced abstinence alter cocaine-seeking behavior and Fos protein expression. Neuroscience 171: 1187-1196.

Wang GJ, Volkow ND, Fowler JS, Cervany P, Hitzemann RJ, Pappas NR et al (1999). Regional brain metabolic activation during craving elicited by recall of previous drug experiences. Life Sci 64: 775-784.

Winterbauer NE, Balleine BW (2007). The influence of amphetamine on sensory and conditioned reinforcement: evidence for the re-selection hypothesis of dopamine function. Front Integr Neurosci 1: 9.

Yahyavi-Firouz-Abadi N, See RE (2009). Anti-relapse medications: preclinical models for drug addiction treatment. Pharmacol Ther 124: 235-247.

Zavala AR, Biswas S, Harlan RE, Neisewander JL (2007). Fos and glutamate AMPA receptor subunit coexpression associated with cue-elicited cocaine-seeking behavior in abstinent rats. Neuroscience 145: 438-452.

Zavala AR, Browning JR, Dickey ED, Biswas S, Neisewander JL (2008). Region-specific involvement of AMPA/Kainate receptors in Fos protein expression induced by cocaine-conditioned cues. Eur Neuropsychopharmacol 18: 600-611. 